\title{
Long-Term Oncological Outcomes for Young Men Undergoing Radical Prostatectomy for Localized Prostate Cancer
}

\author{
Daimantas Milonas, ${ }^{1}$ Zilvinas Venclovas, ${ }^{1}$ Inga Gudinaviciene, \\ Kristina Zviniene, ${ }^{3}$ and Aivaras Jonas Matjosaitis ${ }^{1}$ \\ ${ }^{1}$ Department of Urology, Lithuanian University of Health Sciences, Medical Academy, A. Mickeviciaus 9, \\ LT-44307 Kaunas, Lithuania \\ ${ }^{2}$ Department of Pathology, Lithuanian University of Health Sciences, Medical Academy, A. Mickeviciaus 9, \\ LT-44307 Kaunas, Lithuania \\ ${ }^{3}$ Department of Radiology, Lithuanian University of Health Sciences, Medical Academy, A. Mickeviciaus 9, \\ LT-44307 Kaunas, Lithuania
}

Correspondence should be addressed to Daimantas Milonas; daimantas.milonas@kaunoklinikos.lt

Received 6 January 2017; Accepted 31 January 2017; Published 19 February 2017

Academic Editor: David B. Samadi

Copyright (C) 2017 Daimantas Milonas et al. This is an open access article distributed under the Creative Commons Attribution License, which permits unrestricted use, distribution, and reproduction in any medium, provided the original work is properly cited.

\begin{abstract}
Aim. The aim of this study was to describe PCa characteristics and long-term outcomes in young men aged $\leq 55$ years after radical prostatectomy (RP) and to compare them with older men cohort. Methods. Among 2,200 patients who underwent RP for clinically localized PCa at our centre between 2001 and 2015, 277 (10.3\%) men aged $\leq 55$ years were identified. All preoperative and pathological parameters were compared between groups. Biochemical progression free survival (BPFS) and disease progression free survival (DPFS) were assessed at 5 and 10 years. Results. Men aged $\leq 55$ years had similar pathological tumor characteristics and biochemical recurrence rate $(\mathrm{BCR})$ compared to their older counterparts. Disease progression rate $2.5 \%$ versus $0.4 \%$ was higher in older patients $(p=0.026)$. BPFS rate was not different in both study groups. Estimated 10 -year DPFS was $98.8 \%$ in younger men compared to $89.2 \%$ in their older counterparts $(p=0.031)$. Multivariate Cox regression showed that Gleason score lymph-nodes and surgical margins status were significant predictors for disease progression. Conclusions. In our cohort, men aged $\leq 55$ years had similar pathological PCa characteristics and BCR rate in comparison with older men. RP can be performed with excellent long-term DPFS results in men with localized $\mathrm{PCa}$ at $\leq 55$ years of age.
\end{abstract}

\section{Introduction}

Prostate cancer (PCa) is a disease of the elderly with $80 \%$ of men diagnosed at the age $\geq 65$ [1]. However, PCa diagnosis is not uncommon in younger men, and the proportion of patients with PCa aged $<50$ years has increased from $1 \%$ in the 1970 s to $5 \%$ in the PSA era [2]. Different autopsy studies show high rates of latent PCa in the fourth and fifth decades of age. The prevalence of latent PCa in younger men varies markedly among different autopsy series from $2.6 \%$ in Greek series [3] to a much higher 27\% prevalence in Hungary [4] and up to $34 \%$ in USA [5]. Altogether, the study shows that about $20 \%-30 \%$ of $40-50$-year-old men would harbor a $\mathrm{PCa}$ [6]. The increase of PCa diagnosis at young age raises a number of important questions about their biology and treatment modalities. A 60 -year-old patient with a low risk and Gleason score $6 \mathrm{PCa}$ is a suitable candidate for active surveillance. However, a similar scenario in men aged 45-55 might prompt immediate intervention in majority of cases, because of opinion that PCa detected in young age might behave more aggressively [7] and because young men are more likely to undergo RP [8]. Data about young age men with PCa treatment outcomes are controversial. According to the pre-PSA era studies, younger men are likely to have a more aggressive disease and carry a worse prognosis $[9,10]$. However, more recent studies suggest high rates of indolent $\mathrm{PCa}$ with more favorable outcomes in young men after radical prostatectomy (RP) compared to their older counterparts 
[11-13]. A common limitation of these studies was prostate specific antigen (PSA) relapse used as endpoint of oncological outcomes, whereas disease progression or cancer related death should be the optimal endpoint in order to provide more generalizing conclusions.

The twofold aim of our study was to determine whether younger men had more favorable pathological findings and oncological outcomes (biochemical recurrence rate (BCR) and disease progression) in comparison with older counterparts and to evaluate prognostic risk factors for disease progression after RP.

\section{Patients and Methods}

Between 2001 and 2015, 2,200 men were treated with RP for clinically localized PCa at a single university hospital centre. We identified 277 men aged $\leq 55$ years at time of RP. Clinical characteristics such as PSA level, clinical stage, and biopsy Gleason score were reported before RP. Pathological parameters (pathological stage, Gleason score, surgical margin status, and lymph nodes status) were collected after surgery. PSA testing after RP was performed every three months in the first year, biannually in the second and third year, and once a year thereafter. BCR was identified as a PSA value of $>0.2 \mathrm{ng} / \mathrm{ml}$ in two consequent measurements. Disease progression was identified upon skeletal lesions confirmation by bone scan, CT, or MRI using RECIST criteria. Local recurrence was confirmed by histological investigation after surgery or biopsy. Pathological stage was assessed using 2002 TNM system, and tumor grading was classified using the Gleason grading system (2001-2005) and the revised 2005 Gleason grading system afterwards. Histopathological investigation in the majority of cases was performed by one uropathologist I.G. Adjuvant therapy (radiation therapy (RT) alone or RT + androgen deprivation therapy) was performed depending on the pathological characteristics of PCa within four months after RP, and salvage therapy (radiation therapy (RT) alone or RT + androgen deprivation therapy) was applied after detecting BCR. Prospective collection of data was approved by the university's ethical committee, and all patients signed a consent form provided before RP.

Clinical, pathological, and follow-up data (time to BCR, time to detected metastasis, or local recurrence) were compared between men aged $\leq 55$ years at time of RP and older patients. The chi-square test for nominal variables and the $t$ test for continuous variables were used to compare baseline clinical and pathological characteristics. BPFS and DPFS rates for each study group were estimated using Kaplan-Meier analysis. The long-rank test was used to compare survival of younger versus older men. Men who underwent adjuvant therapy without BCR were excluded from BPFS analyses. The impact of baseline parameters on disease progression was assessed by bivariate and multivariate Cox regression analyses adjusted for clinical stage, preoperative PSA level, biopsy Gleason score, pathological stage, pathological Gleason score, lymph nodes, and surgical margins status. For this analysis PSA value was categorized to $\leq 4.0$ versus $4.1-10$ versus $10.1-20.0$ versus $>20.0 \mathrm{ng} / \mathrm{ml}$.

\section{Results}

The number of men aged $\leq 55$ years treated by $\mathrm{RP}$ in our centre increased significantly from $2.8 \%$ in 2003 to $15.5 \%$ in 2015. Within presented study cohort (Table 1), younger men aged $\leq 55$ years were more likely to present with low PSA level ( $p=0.038)$, clinically organ confined disease $(p<0.001)$, and less aggressive tumor according to biopsy Gleason score $(p=0.046)$. Pathological PCa stage $(p=$ $0.1)$, grade $(p=0.37)$, and positive lymph nodes rate $(p=$ 0.85 ) were not different comparing young men with older counterparts. BCR was similar between groups and reached 29\% during median 50 months overall follow-up; metastases were detected at significantly higher rate in older men $(p=$ $0.026)$. Skeletal disease progression lesions were detected in 40 of $50(80 \%)$ cases, and in $10(20 \%)$ cases local metastatic process was confirmed histologically after salvage surgery or biopsy. The median time to disease progression was 43 months in men aged $>55$ years versus 54 months in younger men.

The Kaplan-Meier analysis showed similar BPFS rate (Figure 1 ) for men aged $\leq 55$ years and older patients (2-, 5, and 8 -year BPFS was $85.9 \%, 77.9 \%$, and $72.4 \%$ versus $82.8 \%$, $73.7 \%$ and $63.7 \%$, resp.; log rank $p=0.57$ ); therefore different estimated DPFS rate (Figure 2) was detected between study groups (5- and 10-year DPFS was $98.8 \%$ and $98.8 \%$ versus 96.9\% and $89.2 \%$ resp.; $\log$ rank $p=0.031$ ).

Bivariate regression analysis revealed that almost all pre- and postoperative parameters, except patients' age and PSA below $20 \mathrm{ng} / \mathrm{ml}$, are predictors for disease progression and Gleason score was most significant of them (Table 2). Multivariate Cox regression analysis shows that pathological Gleason score, positive surgical margins, and lymph nodes were mostly significant predictors of disease progression (Table 3 ). Patients' age ( $\leq 55$ versus $>55$ years of age) failed to reach significant predictor status.

\section{Discussion}

Age at the detection of cancer is a well-recognized prognostic factor in a patient with majority localizations of malignancy. Although few studies demonstrated an association of a young age and high stage of PCa with worse prognosis $[9,10]$, data from recent studies have shown that earlier diagnosis of $\mathrm{PCa}$ in young men is associated with low grade and stage disease or even with superior outcome [11-13].

Becker et al. presented data of more than 13 thousand men who underwent RP at a single centre [13]. The authors compared men aged $<50$ and $\geq 50$ years and detected a significant difference in pathological grade and stage between groups favorable to younger patients. Similar findings were presented by some other authors $[11,12]$. Twiss et al. demonstrated opposite results in their analysis of 790 men after RP. These authors did not detect difference in preoperative and pathologic predictors of organ-confined disease and BCR between men aged $<50$ years and older [14]. Our data also showed that the proportion between organ-confined $(70.4 \%$ versus $65.5 \%)$, locally advanced (29.6\% versus $34.5 \%)$, low grade (Gleason score $\leq 3+4,83.4 \%$ versus $80.6 \%$ ), and high 
TABLE 1: Clinical and pathologic features of men undergoing prostatectomy.

\begin{tabular}{|c|c|c|c|}
\hline Parameter & Age $\leq 55(n=277)$ & Age $>55(n=1.923)$ & $p$ \\
\hline Follow-up (mo), median (quartiles) & $48.5(24.0-77.3)$ & $50.0(24.0-79.3)$ & 0.8 \\
\hline PSA (ng/mL), median (quartiles) & $5.8(4.5-9.0)$ & $6.36(4.8-9.5)$ & 0.038 \\
\hline \multicolumn{4}{|l|}{ Clinical stage, $n(\%)$} \\
\hline cT1 & $104(37.5)$ & $565(29.4)$ & \\
\hline $\mathrm{cT} 2$ & $154(55.6)$ & $1098(57.1)$ & 0.001 \\
\hline cT3 & $19(6.9)$ & $260(13.5)$ & \\
\hline \multicolumn{4}{|l|}{ Pathological stage, $n(\%)$} \\
\hline pT2 & $195(70.4)$ & $1260(65.5)$ & \\
\hline pT3a & $70(25.3)$ & $519(27.0)$ & 0.1 \\
\hline pT3b & $12(4.3)$ & $144(7.5)$ & \\
\hline \multicolumn{4}{|l|}{ Biopsy GS, $n(\%)$} \\
\hline $3+3$ & $183(66.1)$ & $1,125(58.5)$ & \\
\hline $3+4$ & $77(27.8)$ & $597(31.0)$ & \\
\hline $4+3$ & $10(3.6)$ & $75(3.9)$ & 0.046 \\
\hline 8 & $5(1.8)$ & $87(4.5)$ & \\
\hline $9-10$ & $2(0.7)$ & $39(2.0)$ & \\
\hline \multicolumn{4}{|l|}{ Pathological GS, $n(\%)$} \\
\hline $3+3$ & $78(28.2)$ & $539(28.0)$ & \\
\hline $3+4$ & $153(55.2)$ & $1,011(52.6)$ & \\
\hline $4+3$ & $28(10.1)$ & $183(9.5)$ & 0.37 \\
\hline 8 & $11(4.0)$ & $89(4.6)$ & \\
\hline $9-10$ & $7(2.5)$ & $101(5.3)$ & \\
\hline \multicolumn{4}{|l|}{ Pathological nodal status, $n(\%)$} \\
\hline No & $65(23.5)$ & $619(32.2)$ & \\
\hline N1 & $7(2.5)$ & $62(3.2)$ & 0.85 \\
\hline \multicolumn{4}{|l|}{ Surgical margins status, $n(\%)$} \\
\hline R0 & $214(80.5)$ & $1482(80.1)$ & \\
\hline $\mathrm{R} 1$ & $52(19.5)$ & $368(19.9)$ & 0.92 \\
\hline PSA relapse, $n(\%)$ & $79(28.5)$ & $544(28.3)$ & 0.9 \\
\hline Disease progression, $n(\%)$ & $1(0.4)$ & $49(2.5)$ & 0.026 \\
\hline
\end{tabular}

PSA: prostate specific antigen, GS: Gleason score.

grade (Gleason score $\geq 4+3,17.6 \%$ versus $19.4 \%$ ) disease was similar when comparing young men and older counterparts, respectively. This suggests that data regarding pathological findings after RP in young men are still controversial. Therefore, data from recent studies confirm that pathological PCa characteristics in young men are not more aggressive than in older men.

Long-term BFSR for young men cohort presented in various studies is high. Becker et al. reported $80.7 \%$ and $63.0 \%$ estimated 5 - and 10 -year BFSR for men aged $<50$ years, and it was significantly higher $(p=0.006)$ compared to the older counterparts [13]. Freedland et al. presented 6year BFSR data according to the decade of life in 1,753 men after RP and showed that men younger than 50 years of age had significantly higher BFSR compared to other groups [11]. Parker et al. also detected significantly lower BCR rate and highest BPFS among men aged $<50$ years versus all other age groups in their analysis of 5,195 men after RP [12]. In our study, 5- and 8-year BFSR was $77.9 \%$ and $72.4 \%$, respectively, for young men, but the difference compared to men aged $>55$ years was not significant ( $p=0.57$ ). Looking at the data of all mentioned publications, we would like to emphasize that age at the time of surgery failed to achieve independent predictor status in multivariable analysis in most studies.

PSA relapse is not always associated with disease progression; therefore, behaviour of cancer could be estimated by disease progression or cancer related death. In present study, only one case $(0.4 \%)$ of metastatic disease was detected in men aged $\leq 55$ year compared to 49 cases $(2.5 \%)$ in older men $(p=0.026)$. In presented cohort bivariate Cox proportional hazards model showed that clinical stage and biopsy Gleason score are significant predictors for disease progression, and the highest hazard ratio was detected for very poorly differentiated cancer (Gleason score 9-10). Preoperative PSA only at value $>20 \mathrm{ng} / \mathrm{ml}$ could influence PCa progression. Younger patients age $\leq 55$ years did not reach substantial level as independent parameter $(p=0.07)$. All pathological parameters in bivariate analysis were detected as highly significant predictors for disease progression $(p=0.001)$. Multivariate analysis shows that only some pathological 
TABLE 2: Bivariate Cox proportional hazards analysis of factors predicting time to disease progression after radical prostatectomy.

\begin{tabular}{|c|c|c|c|}
\hline Parameter & Hazard ratio & CI $95 \%$ & $p$ \\
\hline \multicolumn{4}{|l|}{ Clinical stage (cT): } \\
\hline cT2 versus cT1 & 3.2 & $1.8-7.6$ & 0.011 \\
\hline cT3 versus cT1 & 6.8 & $2.4-9.6$ & 0.001 \\
\hline \multicolumn{4}{|l|}{ Pathological stage ( $\mathrm{pT})$ : } \\
\hline pT3a versus pT2 & 3.7 & $1.7-8.1$ & 0.001 \\
\hline $\mathrm{pT} 3 \mathrm{~b}$ versus $\mathrm{pT} 2$ & 17.5 & $8.3-36.8$ & $<0.001$ \\
\hline \multicolumn{4}{|l|}{ PSA (ng/ml) } \\
\hline $4.1-10$ versus $\leq 4$ & 1.3 & $0.4-3.7$ & 0.7 \\
\hline $10.1-20$ versus $\leq 4$ & 2.1 & $0.7-6.4$ & 0.2 \\
\hline$>20$ versus $\leq 4$ & 5.3 & $1.6-16.9$ & 0.005 \\
\hline \multicolumn{4}{|l|}{ Biopsy GS: } \\
\hline $3+4$ versus $3+3$ & 3.8 & $1.9-7.9$ & $<0.001$ \\
\hline $4+3$ versus $3+3$ & 7.7 & $2.5-23.7$ & $<0.001$ \\
\hline $4+4$ versus $3+3$ & 6.8 & $2.4-19.1$ & $<0.001$ \\
\hline$\geq 4+5$ versus $3+3$ & 52.9 & $19.8-141.1$ & $<0.001$ \\
\hline \multicolumn{4}{|l|}{ Pathological GS: } \\
\hline $3+4$ versus $3+3$ & N.D & N.D & N.D \\
\hline $4+3$ versus $3+3$ & 16.8 & $4.1-68.7$ & $<0.001$ \\
\hline $4+4$ versus $3+3$ & 24.6 & $6.6-92.1$ & $<0.001$ \\
\hline$\geq 4+5$ versus $3+3$ & 114.0 & $30.9-421.6$ & $<0.001$ \\
\hline \multicolumn{4}{|c|}{ Lymph nodes status ( $\mathrm{pN})$ : } \\
\hline N1 versus N0 & 4.5 & $2.0-9.9$ & 0.001 \\
\hline \multicolumn{4}{|l|}{ Surgical margins: } \\
\hline $\mathrm{R} 1$ versus $\mathrm{R} 0$ & 5.6 & $2.9-10.9$ & $<0.001$ \\
\hline \multicolumn{4}{|l|}{ Age, years } \\
\hline$\leq 55$ versus $>55$ & 6.4 & $0.9-46.3$ & 0.07 \\
\hline
\end{tabular}

PSA: prostate specific antigen, GS: Gleason score.

TABle 3: Multivariate Cox proportional hazards analysis of factors predicting time to disease progression after radical prostatectomy.

\begin{tabular}{lccc}
\hline Parameter & Hazard ratio & CI 95\% & $p$ \\
\hline Clinical stage & 1.1 & $0.6-1.5$ & 0.1 \\
Pathological stage & 1.2 & $0.7-2.0$ & 0.6 \\
PSA (ng/ml) & 1.0 & $0.7-1.5$ & 0.9 \\
Biopsy GS & 1.1 & $0.8-1.4$ & 0.6 \\
Pathological GS & 2.4 & $1.7-3.1$ & $<0.0001$ \\
$\quad$ Lymph nodes status & & & \\
$\quad$ N1 versus N0 & 0.39 & $0.15-0.65$ & 0.002 \\
$\quad$ Surgical margins & & & \\
$\quad$ R1 versus R0 & 4.1 & $1.8-9.4$ & 0.001 \\
$\quad$ Age, years & & & \\
$\quad$ 55 versus $>55$ & 0.15 & $0.02-1.1$ & 0.06 \\
\hline
\end{tabular}

PSA: prostate specific antigen, GS: Gleason score.

parameters such as positive lymph nodes ( HR 0.39, $p=$ 0.002 ), positive surgical margins (HR 4.1, $p=0.001$ ), and Gleason score (HR 2.4, $p<0.0001$ ) are important for disease progression. These findings are in concordance with various other studies' data [15-20]. Interestingly enough, no

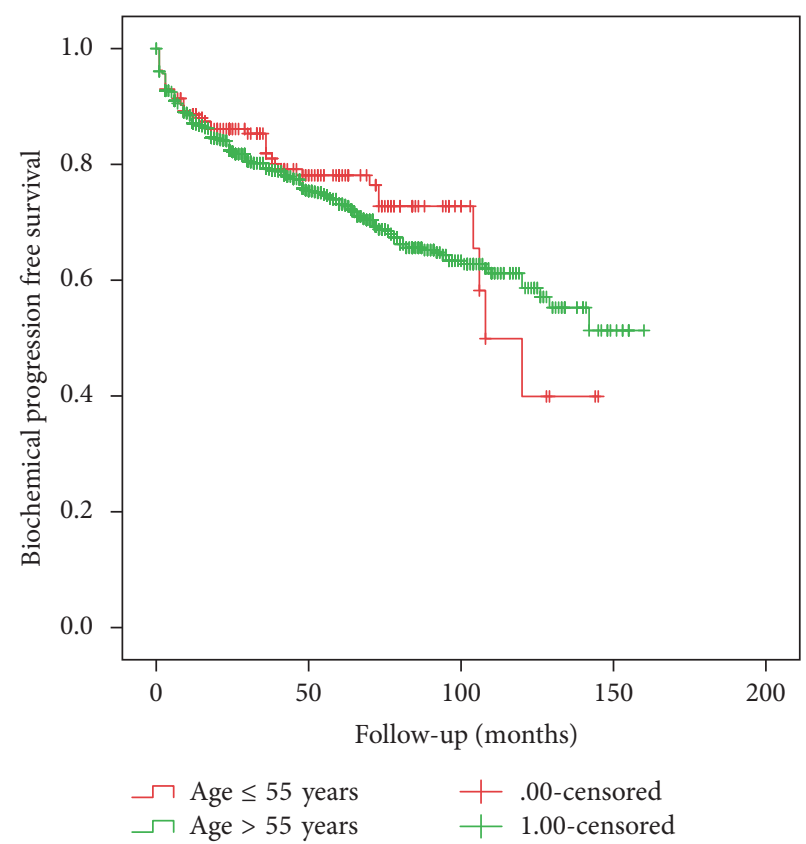

FIgURE 1: Comparison of Kaplan Meier biochemical progression free survival between study groups $(\log \operatorname{rank} p=0.57)$.

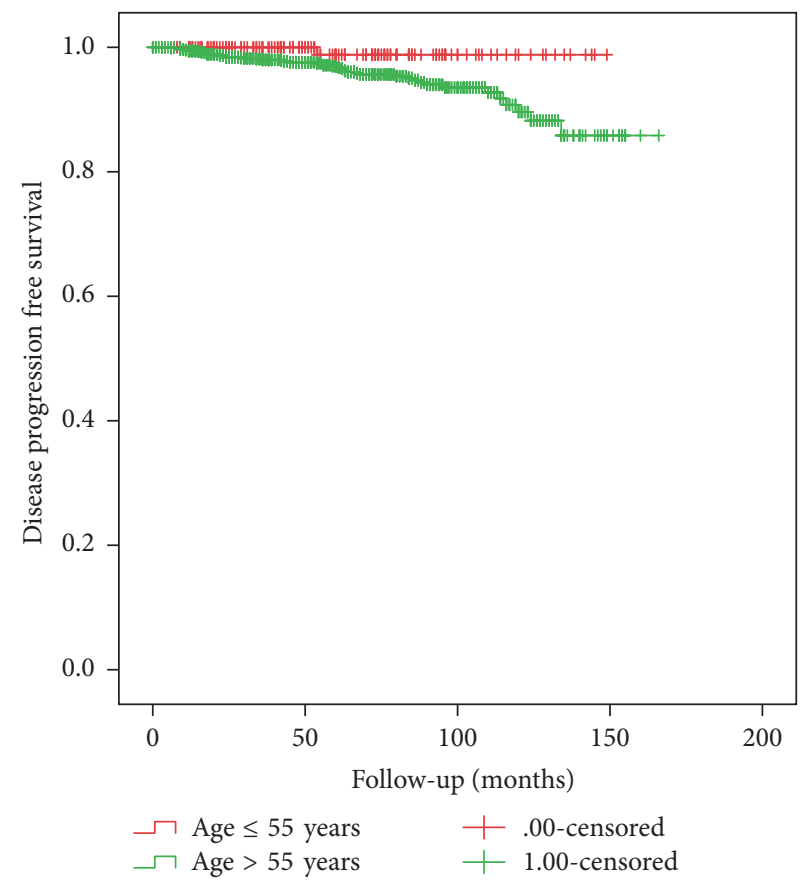

FIgure 2: Comparison of Kaplan Meier disease progression free survival between study groups $(\log \operatorname{rank} p=0.031)$.

difference was detected comparing these parameters between men aged $\leq 55$ years versus $>55$ years in our cohort. Estimated 10 -year DPFS was $98.8 \%$ versus $89.2 \%(p=0.031)$ in favor of men aged $\leq 55$ years. Presented data show that older men are more likely to progress to metastatic disease after a definitive treatment of BCR. More aggressive behavior of 
cancer in older men is unclear and needs more intensive multi-institutional research.

Two possible hypotheses arise trying to explain our study findings. The first one is that older men potentially have a more aggressive disease. Several studies comparing oncological outcomes after RP in young and older men supported such a conclusion [11-14]. In their review of young-age prostate cancer, Hussein et al. noticed that young-age PCa has several biological and genetic features that are distinct from elderly-onset cancer, but in the majority of cases young men tend to have low grade and stage disease. On the other hand, the authors pay attention that early-onset PCa could represent a subset of young-age and familial PCa with more aggressive disease and higher prostate-cancer-specific death rate [6]. Until now, only two factors (family history and race) are confirmed to have close relationship with the detection of PCa in young men $[21,22]$, but the data about its aggressiveness is controversial. We did not find more aggressive disease characteristics in younger men while comparing postoperative data, but higher disease progression rate in elderly patients directly supports the hypothesis that we have raised. The pathomechanism of such behavior is unclear and needs further research. Our second hypothesis is biologically agerelated decreasing possibilities against disease progression and lower response of older patients to additional treatment after PSA relapse. No difference in grade, stage, lymph nodes involvement, and BCR rate logically suggests that additional conditions play an important role in disease progression. More long-term clinical data are needed to confirm our findings. In general, the results of present study regarding oncological outcomes indicate that young men with $\mathrm{PCa}$ could be suitable candidates for all treatment modalities.

The choice of treatment strategy depends not only on oncological outcomes, but also on the quality of life after definitive treatment. Continence and erectile function are most important parameters that concern men after the treatment they underwent. ProtectT trial regarding these two parameters shows significant inferiority of RP when compared to radiation therapy and active surveillance [23], and we should agree that RP harbors increasing risk of functional adverse events. Therefore, if we look at the data analyzing young men's population, continence end erectile function recovery rate is very high and reaches $95 \%$ and $80 \%$, respectively, that is a significantly higher rate in comparison with older counterparts $[13,14]$. The most important predictor for preservation of erectile function is nerve-sparing procedure $[13,14]$ that is strongly recommended in cases of young age and organ confided disease. So, we can conclude that men in young age with localized PCa are suitable candidates for surgical treatment with good DP control and low functional adverse events rate after RP.

The present study is not devoid of limitations. A relatively short follow-up is one of them. The absence of other treatment modality group and direct comparison of results is another limitation of our study. Although disease progression, not death from cancer, was chosen as the end point of this study, looking at our results we hope that the analysis of cancer specific mortality would show similar tendencies.
The strength of the present study is prospectively collected data, pathological investigation by one experienced pathologist in majority of cases, standard evaluation of disease progression, and treatment of BCR. To our knowledge, this study is the first one to describe disease progression free survival as end point in young patients cohort after RP.

\section{Conclusions}

The presented analysis of a large, single centre's cohort of men after RP indicates that young patients aged $\leq 55$ years have similar histopathology and BCR rate after surgery for localized PCa compared to older counterparts. However, young patients have a significantly lower risk for disease progression in long-term follow-up and men aged $\leq 55$ years with localized PCa should not be discouraged from radical treatment.

\section{Competing Interests}

The authors declare that there is no conflict of interests regarding the publication of this paper.

\section{References}

[1] A. Jemal, R. Siegel, J. Xu, and E. Ward, "Cancer statistics, 2010," CA Cancer Journal for Clinicians, vol. 60, no. 5, pp. 277-300, 2010.

[2] J. Li, R. German, J. King et al., "Recent trends in prostate cancer testing and incidence among men under age of 50," Cancer Epidemiology, vol. 36, no. 2, pp. 122-127, 2012.

[3] K. Stamatiou, A. Alevizos, E. Agapitos, and F. Sofras, "Incidence of impalpable carcinoma of the prostate and of non-malignant and precarcinomatous lesions in Greek male population: an autopsy study," Prostate, vol. 66, no. 12, pp. 1319-1328, 2006.

[4] G. Soos, I. Tsakiris, J. Szanto, C. Turzo, P. G. Haas, and B. Dezso, "The prevalence of prostate carcinoma and its precursor in Hungary: an autopsy study," European Urology, vol. 48, no. 5, pp. 739-744, 2005.

[5] W. A. Sakr, G. P. Haas, B. F. Cassin, J. E. Pontes, and J. D. Crissman, "The frequency of carcinoma and intraepithelial neoplasia of the prostate in young male patients," Journal of Urology, vol. 150, no. 2, pp. 379-385, 1993.

[6] S. Hussein, S. Satturwar, and T. Van der Kwast, "Young-age prostate cancer," Journal of Clinical Pathology, vol. 68, no. 7, pp. 511-515, 2015.

[7] D. W. Lin, M. Porter, and B. Montgomery, "Treatment and survival outcomes in young men diagnosed with prostate cancer," Cancer, vol. 115, no. 13, pp. 2863-2871, 2009.

[8] N. J. Kinnear, G. Kichenadasse, S. Plagakis et al., "Prostate cancer in men aged less than 50 years at diagnosis," World Journal of Urology, vol. 34, no. 11, pp. 1533-1539, 2016.

[9] H. B. Tjaden, D. A. Culp, and R. H. Flocks, "Clinical adenocarcinoma of the prostate in patients under 50 years of age," The Journal of Urology, vol. 93, pp. 618-621, 1965.

[10] D. E. Johnson, J. P. Lanieri, and A. G. Ayala, "Prostatic adenocarcinoma occurring in men under 50 years of age," Journal of Surgical Oncology, vol. 4, no. 3, pp. 207-216, 1972. 
[11] S. J. Freedland, J. C. Presti Jr., C. J. Kane et al., "Do younger men have better biochemical outcomes after radical prostatectomy?" Urology, vol. 63, no. 3, pp. 518-522, 2004.

[12] P. M. Parker, K. R. Rice, J. R. Sterbis et al., "Prostate cancer in men less than the age of 50: a comparison of race and outcomes," Urology, vol. 78, no. 1, pp. 110-115, 2011.

[13] A. Becker, P. Tennstedt, J. Hansen et al., "Functional and oncological outcomes of patients aged $<50$ years treated with radical prostatectomy for localised prostate cancer in a European population," BJU International, vol. 114, no. 1, pp. 38-45, 2014.

[14] C. Twiss, D. Slova, and H. Lepor, "Outcomes for men younger than 50 years undergoing radical prostatectomy," Urology, vol. 66, no. 1, pp. 141-146, 2005.

[15] M. Spahn, S. Joniau, P. Gontero et al., "Outcome predictors of radical prostatectomy in patients with prostate-specific antigen greater than $20 \mathrm{ng} / \mathrm{ml}$ : a European multi-institutional study of 712 patients," European Urology, vol. 58, pp. 1-7, 2010.

[16] B. M. Mian, P. Troncoso, K. Okihara et al., "Outcome of patients with Gleason score 8 or higher prostate cancer following radical prostatectomy alone," Journal of Urology, vol. 167, no. 4 I, pp. 1675-1680, 2002.

[17] J. F. Donohue, F. J. Bianco Jr., K. Kuroiwa et al., "Poorly differentiated prostate cancer treated with radical prostatectomy: longterm outcome and incidence of pathological downgrading," Journal of Urology, vol. 176, no. 3, pp. 991-995, 2006.

[18] M. Manoharan, V. G. Bird, S. S. Kim, F. Civantos, and M. S. Soloway, "Outcome after radical prostatectomy with a pretreatment prostate biopsy Gleason score of $\geq 8$," BJU International, vol. 92, no. 6, pp. 539-544, 2003.

[19] S. Serni, L. Masieri, A. Minervini, A. Lapini, G. Nesi, and M. Carini, "Cancer progression after anterograde radical prostatectomy for pathologic Gleason score 8 to 10 and influence of concomitant variables," Urology, vol. 67, no. 2, pp. 373-378, 2006.

[20] D. Milonas, R. Baltrimavicius, A. Grybas et al., "Outcome of surgery in locally advanced pT3a prostate cancer," Central European Journal of Urology, vol. 64, no. 4, pp. 209-212, 2011.

[21] F. Albright, R. A. Stephenson, N. Agarwal et al., "Prostate cancer risk prediction based on complete prostate cancer family history," Prostate, vol. 75, no. 4, pp. 390-398, 2015.

[22] F. Kamangar, G. M. Dores, and W. F. Anderson, "Patterns of cancer incidence, mortality, and prevalence across five continents: defining priorities to reduce cancer disparities in different geographic regions of the world," Journal of Clinical Oncology, vol. 24, no. 14, pp. 2137-2150, 2006.

[23] J. L. Donovan, F. C. Hamdy, A. J. Lane et al., "Patientreported outcomes after monitoring, surgery, or radiotherapy for prostate cancer," The New England Journal of Medicine, vol. 375, pp. 1425-1437, 2016. 


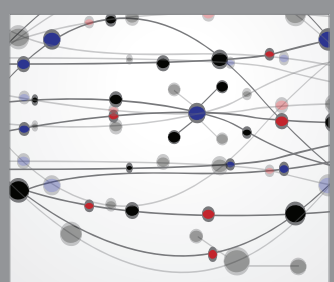

The Scientific World Journal
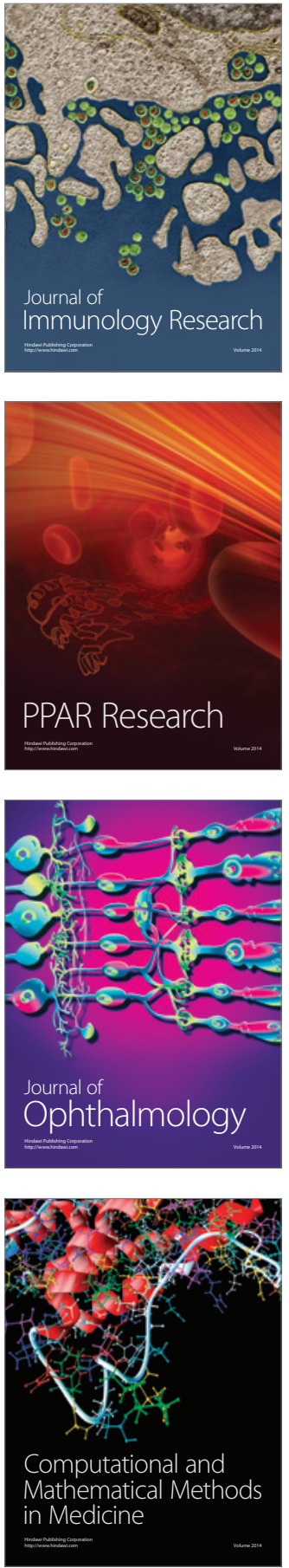

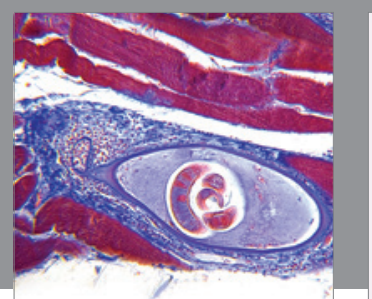

Gastroenterology Research and Practice
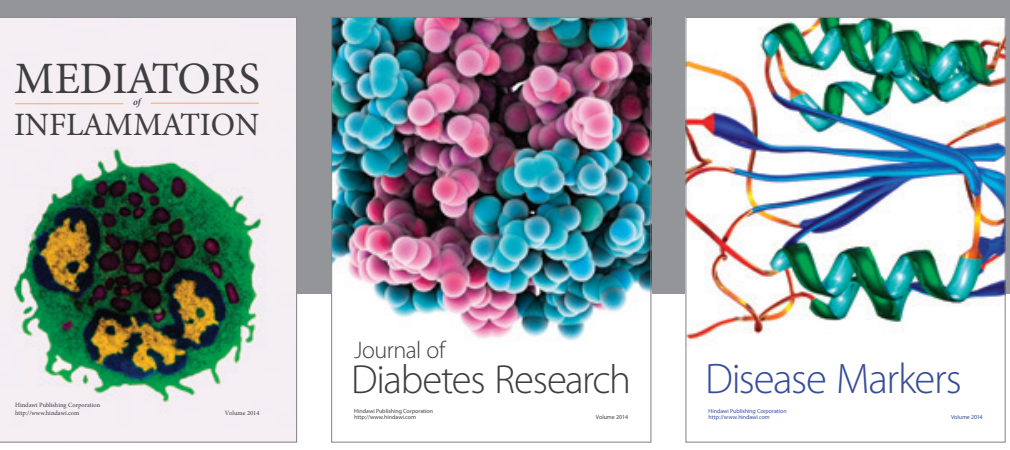

Disease Markers

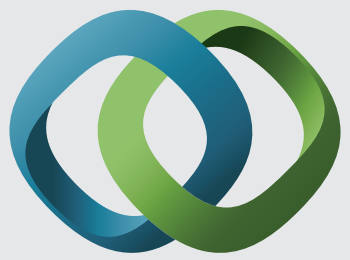

\section{Hindawi}

Submit your manuscripts at

https://www.hindawi.com
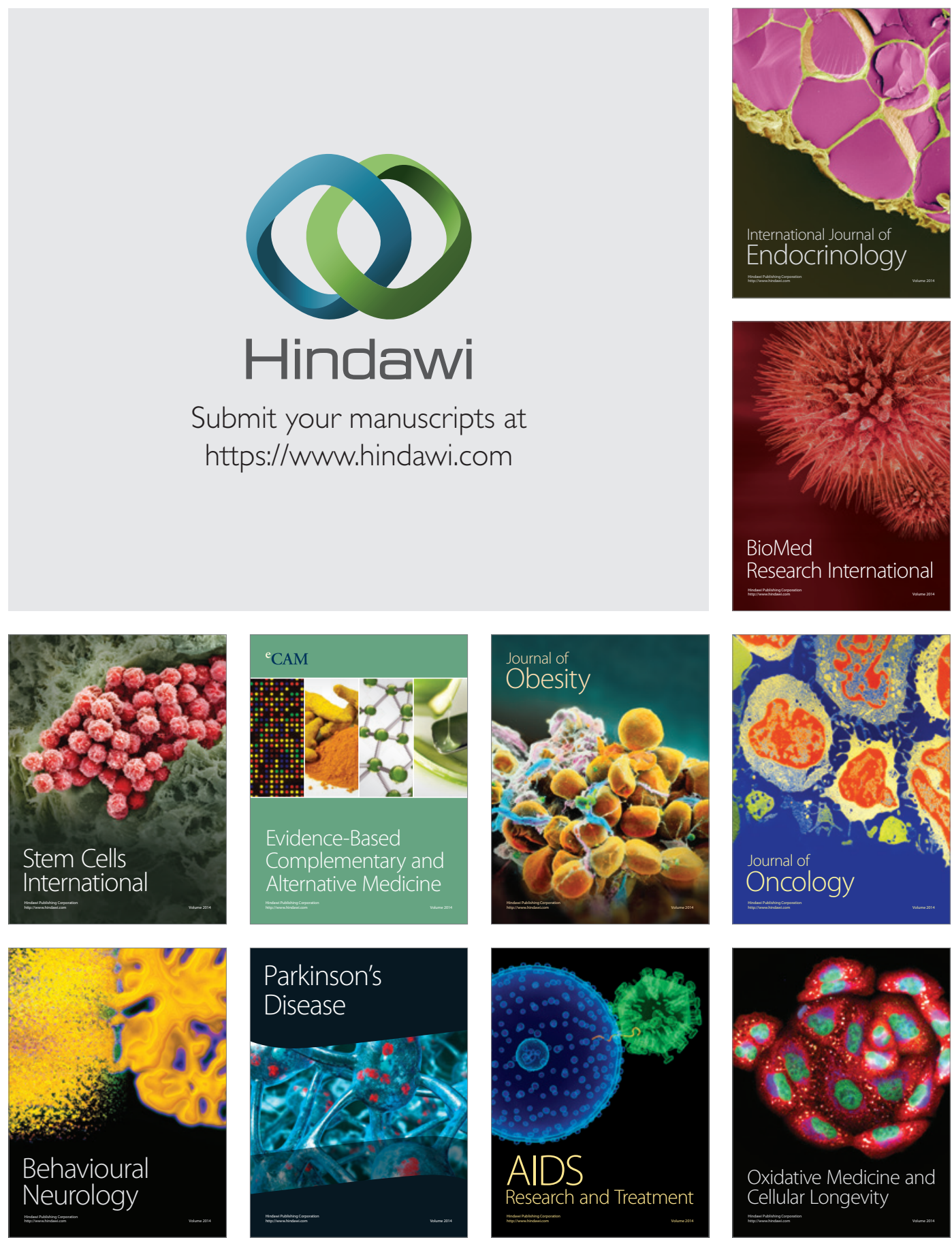